\title{
An Analysis of the Journal of Range Management: Report of the SRM Task Force
}

In response to concerns raised by some scientist members of the Society for Range Management (SRM), on May 14, 2002, SRM President Rod Heitschmidt appointed the SRM Task Force on the Journal of Range Management (JRM). The charge to the Task Force was "To specifically evaluate all aspects of the $J R M$ publication process, including affecting interactions with Rangelands and Trail Boss News, and make recommendations for enhancing $J R M$ quality as it relates to content, format, the publication process, and delivery system."

This was in part to allow for periodic independent review of the journal operations and to address the concerns of some members that the journal may need realignment with current member demographics. The Task Force recognized the review process as an important endeavor because publishing the $J R M$ is the primary scientific outreach activity of the SRM. Publication of $J R M$ is critical for SRM to achieve its goal of "assisting all who work with range resources to keep abreast of new findings and techniques in the science and art of range management."

Publication of $J R M$ also promotes SRM as a primary source of information and experience on rangelands as well as presenting range related research for adoption by other scientific disciplines. Therefore, maintaining a high-quality $J R M$ is of paramount importance to SRM.

On February 3, 2003, the Task Force presented the SRM Board of Directors with their report. The primary goal of the Task Force was to gather information useful for informing the membership and the society's decision makers. A secondary goal was to provide the Board with an array of options as SRM adapts to the changing environment of scientific publishing.

The data presented in the report and in this article are arranged according to rhetorical questions about $J R M$ 's scientific standing, the opportunities for joint publishing and electronic access to $J R M$, and the financial aspects of the current publishing situation within SRM. We rely on these data primarily to support recommendations for continued improvement of $J R M$.

\author{
What is the scientific impact of $J R M$ and has \\ the impact changed in the last several \\ decades? \\ Impact Index.
}

We compared $J R M$ with cohort ecological and agricultural journals on the basis of the impact factor computed by Science Citation Index. The impact factor of $J R M$ increased over the 20-year period at a rate equal to or greater than the increases experienced by agricultural journals (Table 1). Moreover, JRM's impact was roughly equivalent to the Wildlife Society Bulletin in 2001.

However, $J R M$ 's impact increased less rapidly from 1989 to 2001 than did ecological and wildlife journals, and the impact of several new ecological and wildlife journals greatly exceeded $J R M$ s impact in 2001. In both 1980 and 2001, JRM's impact factor lagged behind that of all cohort journals, but the difference was less pronounced in 2001 between $J R M$ and the agricultural journals.

Table 1. Impact factor ${ }^{1}$ computed by Science Citation Index for the Journal of Range Management and ecological and agricultural journals with similar scientific subject matter.

\begin{tabular}{llll}
\hline \hline Journal & 1980 & 1989 & 2001 \\
\hline Journal of Range Management & 0.320 & 0.471 & 0.593 \\
Ecology & 2.158 & 2.482 & 3.704 \\
Ecological Applications (new) & $-\cdots---$ & $\cdots---$ & 3.335 \\
Journal of Applied Ecology & 0.575 & 0.975 & 2.937 \\
Plant Ecology (formerly Vegetatio) & 1.096 & 1.676 & 1.059 \\
Journal of Vegetation Science (new) &.----- & $\ldots .--$ & 1.730 \\
Journal of Wildlife Management & 0.540 & 0.750 & 1.593 \\
Wildlife Society Bulletin & $-\ldots .--$ & 0.286 & 0.617 \\
Agronomy Journal & 0.641 & 0.712 & 0.880 \\
Soil Science Society of America Journal & 1.067 & 1.185 & 1.312 \\
Journal of Animal Science & 1.123 & 1.364 & 1.331 \\
\hline
\end{tabular}

${ }^{\mathrm{j}}$ The impact factor is one of the quantitative tools provided by Journal Citation Reports $($ $(J C R \circledast)$ ) for ranking, evaluating, categorizing, and comparing journals. The impact factor is a measure of the frequency with which the "average article" in a journal has been cited in a period. The impact factor can be used to provide a gross approximation of the prestige of journals in which individuals have been published (The foregoing is taken with little change from ISI Web of Knowledge 2002). The number of review articles and self-citations are artifacts that can influence a journal's impact and ranking are described in an article reproduced in ISI Web of Knowledge (2002). Although the more a publication is cited the higher the impact factor rating it receives, the Citation Index eliminates the bias that could occur with publications with more frequent issues, the bias of large journals, and the bias of older journals. 
Numbers of Citations of Peer Journals.

Using the Web of Science (ISI Web of Science 2002) database, we compared the number of times articles from $J R M$ and three cohort journals were cited in 1981 and 2002 (Table 2). In terms of

Table 2. Number of citations of Journal of Range Management and 3 ecological and agricultural journals with similar scientific subject matter. Number of citations were found with a Web of Science search with the journal name as the key word in a general search.

\begin{tabular}{lrrc}
\hline \hline & & Change (\%) from \\
Journal & 1981 & 2002 & 1981 to 2002 \\
\hline Journal of Range Management & 632 & 1232 & 95 \\
Ecology & 2873 & 6593 & 129 \\
American Midland Naturalist & 874 & 1487 & 70 \\
Agronomy Journal & 2091 & 2751 & 32 \\
\hline
\end{tabular}

change in citations over the 20-year period, $J R M$ compares favorably with Ecology and American Midland Naturalist, and the increase in JRM citations exceeded Agronomy Journal. JRM citations in 2002 were less than American Midland Naturalist, an ecological journal that publishes rangeland ecology and management papers. This indicates improvement in number of citations from $J R M$ should be a goal. As is the case for impact factor, larger numbers of citations can result for reasons other than increasing scientific impact. However, growth in number of $J R M$ citations demonstrates that $J R M$ has the potential for a significant increase in scientific impact.

Answer: Scientific impact of $J R M$, as measured by the impact factor and number of citations, compares favorably with agricultural journals, which are declining relative to the ecological and wildlife journals. Rather than indicating an outright decline in scientific impact, these data suggest $J R M$ 's impact has the potential to increase greatly should $J R M$ be perceived by the broader scientific community more as an ecological or natural resource journal than an agricultural journal.

Have the science topics published in JRM and the authors who publish them changed in the last several decades?

We surveyed all articles published within threeyear periods at the turn of each of the previous three decades to determine if subject matter and author affiliation changed over time. Our objective was to

\section{Task Force Members}

David M. Engle, Chair

Department of Plant and Soil Sciences

Oklahoma State University

Stillwater OK 74078

dme@mail.pss.okstate.edu

Joel R. Brown

Jornada Experimental Range

New Mexico State University

Las Cruces, NM 88003-0003

joelbrow@nmsu.edu

Jeffrey S. Fehmi

US Army Corps of Engineers

Construction Engineering Research Laboratory

Champaign, IL 61826-9005

j-fehmi@,cecer.army.mil

Samuel D. Fuhlendorf

Oklahoma State University

Department of Plant and Soil Sciences

Stillwater, OK 74078

fuhlend@mail.pss.okstate.edu

Robert L. Gillen

USDA-ARS

Southern Plains Range Research Station

Woodward, OK 73801

bgillen@spa.ars.usda.gov

M. Keith Owens

Texas Agricultural Experiment Station

Uvalde, TX 78801

m-owens@tamu.edu

determine if $J R M$ was publishing fewer articles in the core topics associated with the ecology and management of rangelands as opposed to those subjects associated with the science of various uses of rangelands or forages (i.e., livestock management and agronomy).

Agricultural science has increased markedly over the 40 -year period to account for $37 \%$ of the published papers in the 1999-2001 sampling period as compared to $15 \%$ in the $1959-61$ sampling period 
Table 3. Proportion (\%) of articles within 9 subject matter categories appearing within the Journal of Range Management in 3 time periods (data in rows represent the sums of 3 years of each period.

\begin{tabular}{lccc}
\hline \hline Subject category & $1959-1961$ & $1979-1981$ & $1999-$ \\
& & & 2001 \\
\hline Livestock management on rangelands $^{1}$ & 5 & 9 & 23 \\
Vegetation management and restoration $^{2}$ & 10 & 14 & 10 \\
Wildlife/habitat management $^{3}$ & 0 & 15 & 8 \\
Agronomy and Agro-forestry $^{4}$ & 10 & 9 & 14 \\
Ecology $^{5}$ & 31 & 26 & 23 \\
Monitoring/Techniques $^{6}$ & 25 & 13 & 7 \\
Hydrology/Watershed $^{7}$ & 2 & 5 & 4 \\
Socio-economics $^{8}$ & 3 & 4 & 5 \\
Other & 15 & 5 & 5 \\
\hline
\end{tabular}

Grazing management, livestock supplementation, livestock nutrition, etc.

${ }^{2}$ Weed and brush control, revegetation, prescribed burning, "range improvements," etc.

${ }^{3}$ Species habitat requirements, habitat management, overlap with domestic livestock if emphasis is on wildlife, and wildlife habitat preferences.

${ }^{4} \mathrm{All}$ aspects of introduced forage species; grazing in forests and woodlands managed primarily for timher and wood products.

5 Organismal ecology and community ecology and the ecology associated with range management practices (e.g., the ecology of preseribed hurning) including the theory of rangeland health/condition analysis.

${ }^{6}$ Theory and practice of monitoring on rangelands; measurement techniques including remote sensing and GIS

${ }^{7}$ Fundamental studies and studies in which the emphasis is on hydrology or watershed even if couched in other subjects (e.g., grazing management).

${ }^{8}$ Social and economic aspects of rangeland management in which the emphasis is on hydrology or watershed even if couched in other subjects (e.g., grazing management)
(Table 3). Papers on ecology and monitoring/techniques declined from $56 \%$ in $1959-61$ to $30 \%$ in 1999-2001. Although the reasons for these changes are uncertain, the increase in agricultural papers could be tied to joint publishing of $J R M$ with the American Forage and Grassland Council (AFGC). This suggests that the continued similarity of $J R M \mathrm{~S}$ impact factor to that of the impact factor of agricultural journals (Table 1) has been supported by the increasing proportion of papers published in $J R M$ with a focus on agricultural use.

Authorship has changed little in the past 20 years. The greatest change in authorship occurred between 1959-61 and 1979-81, with USDA agencies experiencing greater than $50 \%$ decline in authorship (Table 4). The largest gain in authorship has come from universities affiliated with administrative units other than Range Science Education Council (RSEC) affiliated departments/units. Author-ship from RSEC institutions increased from $1959-61$ to $1979-81$ but authors from other university affiliations published a greater proportion of papers by the 1999-2001 period. This change is likely a reflection of the recent trend of downsizing of range departments coupled with an increase in the number of papers authored by agronomists.

Answer: $J R M$ is now publishing a greater proportion of agricultural papers, and the proportion of papers from more traditional rangeland topics has declined concomitantly. Authorship affiliation changed most between 1960 and 1980 when authorship by USDA agencies declined markedly. The proportion of authors from RSEC schools is now less than that of authors of schools not affiliated with RSEC, and most likely, not affiliated with the profession of range management.

\section{Where are SRM scientists publish- ing and has this changed?}

We chose the nine researchers who received SRM's Outstanding Young Range Professional Award from 1988 to 2002 as a sample of SRM scientists who would likely publish in JRM. We assessed publishing history using Web of Science and report publications of those in the group whose publications are indexed on Web of Science.

$J R M$ accounted for the majority of articles published by these nine researchers (Table 5), which indicates these researchers have functioned primarily
Table 4. Proportion (\%) of articles published by authors in 5 affiliations appearing within the Journal of Range Management in 3 time periods ${ }^{1}$.

\begin{tabular}{lccc}
\hline \hline Primary author institutional affiliation & $1959-61$ & $1979-81$ & $1999-2001$ \\
\hline RSEC unit/department ${ }^{2}$ & 23 & 32 & 30 \\
Other university affiliation $^{3}$ & 14 & 28 & 36 \\
USDA agencies $^{4}$ & 46 & 22 & 19 \\
Other agency $^{5}$ & 15 & 15 & 14 \\
Private6 & 2 & 3 & 1 \\
\hline
\end{tabular}

Total number of articles: 301 . Authorship is attributed to the senior author at the time of the research (i.e., or second author in the case of graduate students).

${ }^{2}$ Current member of the Range Science Education Council.

${ }^{3}$ Any U.S., Canadian, Mexican, or other university (world-wide) not a current member of RSEC. Includes departments or similar administrative units of agronomy, wildlife, or animal science universities in which the RSEC department/administrative unit is separate.

${ }^{4}$ All USDA agencies including ARS, NRCS (SCS), and USFS with the majority represented by ARS.

${ }^{5}$ Any other agency, world-wide, either federal or state/provincial. Representative agencies in the U.S. include state wildlife agencies, agencies in the U.S. Department of Interior, and agencies such as the Agriculture and Agri-Food Canada outside the U.S.

${ }^{6}$ Any private individual or non-governmental organization (e.g., The Nature Conservancy) 
Table 5. Refereed journal articles published by 9 researchers who received the Outstanding Young Range Professional Award, 1988 to 2002. The authorship was either first or second (i.e., not third or more). All articles would have been acceptable subject matter for $J R M$.

\begin{tabular}{lccc}
\hline \hline Journal & $\begin{array}{c}\text { Articles } \\
\text { published (n) }\end{array}$ & $\begin{array}{c}\text { Articles published } \\
\text { (\% of total) }\end{array}$ & $\begin{array}{c}\text { Number } \\
\text { of journals }\end{array}$ \\
\hline J. Range Management & 71 & 52 & 1 \\
Agricultural $^{1}$ & 17 & 13 & 6 \\
Ecological and other $^{2}$ & 48 & 35 & 37 \\
\hline
\end{tabular}

Grass and Forage Science, Journal of Animal Science, Weed Technology, Agronomy Journal, Applied Animal Behavior Science, and AgroForestry Systems

${ }^{2}$ Such as Oecologia, Wildlife Society Bulletin, American Journal of Botany, American Midland Naturalist.

as range scientists. A minority of their publications appeared in agricultural journals, indicating these researchers are, on the whole, associated more with the ecology and ecological journals (to include $J R M$ ) than with agriculture and agricultural journals.

The group published in a large number $(n=44)$ of journals from 1980-2002 (Table 5). Obviously, the competition for alternative publication outlets is intense. These data validate our personal observation that $J R M$ faces increasing competition from journals published by a myriad of professional society and commercial publishers.

The proportion of articles published in JRM by these researchers has dropped since the high point in the initial observation period of 1980-84, and the drop was dramatic after 1994 (Table 6). This emphasizes that other journals are competing effectively with $J R M$ for articles from SRM's own range scientists.

Answer: $J R M$, as the publication outlet of choice by SRM scientists, is declining, and the options available for publication are increasing. Moreover, SRM scientists are choosing ecological journals in strong preference to agricultural journals. This suggests that if SRM chooses to publish a scientific journal that represents its core scientist members, the journal should resemble more of an ecological journal and less of an agricultural journal.

\section{Has the contribution of $J R M$ to science changed and would it leave a scientific void for rangeland science if $J R M$ would cease to exist?}

As a sample of the body of literature inclusive of range science, we chose articles on the Chihuahuan Desert, a major rangeland area in the U.S. We ana-
Table 6. Refereed journal articles in 5 time periods published by 9 researchers who received the Outstanding Young Range Professional Award, 1988 to 2002. The authorship was either first or second (not third or more). All articles would have been acceptable subject matter for $J R M$.

\begin{tabular}{lccc}
\hline \hline Period & Total articles (n) & JRM articles (n) & JRM articles $(\%)$ \\
\hline $1980-1984$ & 17 & 12 & 71 \\
$1985-1989$ & 16 & 7 & 44 \\
$1990-1994$ & 38 & 17 & 45 \\
$1995-1999$ & 36 & 9 & 25 \\
$2000-2002^{\prime}$ & 29 & 9 & 31 \\
\hline
\end{tabular}

${ }^{1}$ Report for 2002 was incomplete at the time of the survey.

lyzed citations from an extensive bibliography containing 629 references on the Chihuahuan vegetation published from 1906 to 2002 (Hochstrasser et al. 2002). The number of citations per year shows that $J R M$ is one of the most important outlets for Chihuahuan research with more than 20 articles for each of the last two decades (Fig. 1).

$J R M$ is followed by Journal of Arid Environments, which published 15 articles in the 80 s and nearly 30 in the 90 s. It appears that Journal of Arid Environments will be the dominant journal in the future. The next nearest journal is Ecology with 6 articles in the $80 \mathrm{~s}$ and 18 in the $90 \mathrm{~s}$. JRM remains a major research outlet for this region and would leave a void if it no longer accepted papers on the Chihuahuan Desert. However, because 89 different journals were cited, and new outlets appear continually, the void would likely be quickly filled.

Based on percentage of articles published, JRM remains a primary player in Chihuahuan Desert lit-

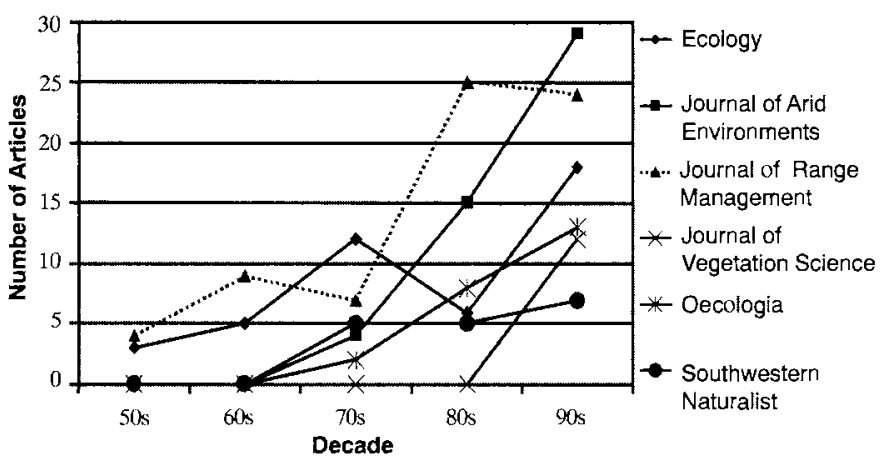

Fig. 1. Number of articles published per decade on the Chihuahuan Desert by those journals having published $>6$ articles in any year from 1950 to 2000. 


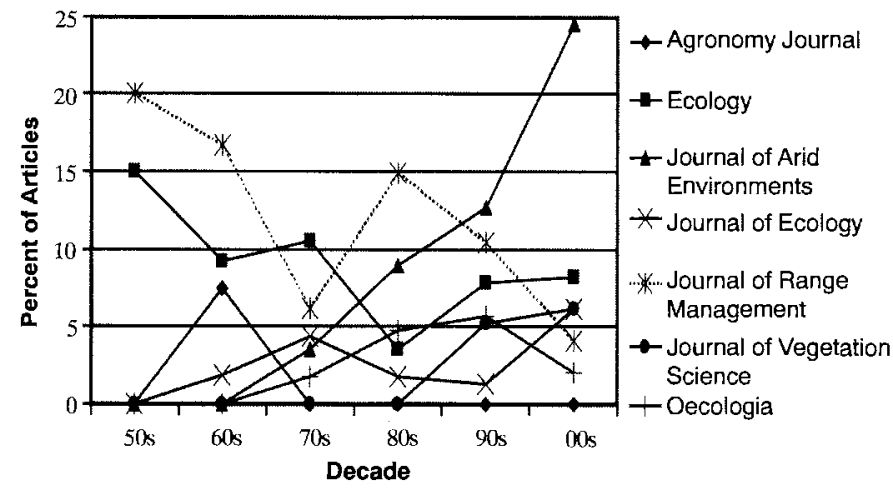

Fig. 2. Percentage of articles published per decade on the Chihuahuan Desert by those journals having published $>6 \%$ of the articles in any year from 1950 to 2000.

erature, but the relative role of $J R M$ has been diminished (Fig. 2). During the 1950 s, $20 \%$ of all Chihuahuan Desert research appeared in JRM followed closely by Ecology with $15 \%$. Although the trend is not without some uncertainty, JRM has declined in importance relative to the overall body of literature since the 1950's, and Journal of Arid Environments has become dominant.

Answer: These data indicate declining impact of $J R M$ in this area of rangeland science. On the other hand, one could argue that the total number of articles has increased and because $J R M$ has a finite number of pages, the effect is an artifact of increased research publication. Overall, these data provide the impression that $J R M$ is about what it has always been in terms of publishing Chihuahuan Desert articles. Further study is needed to determine if $J R M$ provides a meaningful share of the "core" research, i.e., that advance the science in broad terms, as compared to research that is largely mensurative and observational work.

\section{How do similar societies publish science? If $J R M$ were to emulate the most effective model, what would be the benefits and costs?}

The world of scientific journal publication is constantly changing. The rapid acceleration of knowledge acquisition and the use of computers and the internet to find and organize information has caused radical changes. In this environment, the $J R M$ must be continually evaluated and improved to keep pace.

With this in mind, we developed a comparison of the $J R M$ with 13 other scientific journals that are oriented to the management of natural resources and have similar subject contents. Our evaluation was specifically aimed at method of publication, subscription and page charges, and electronic publishing.

Fourteen journals were surveyed, including $J R M$ (Table 7). Of these, three are published by for-prof-

Table 7. Type of publication, publisher, and prices for various journals in the natural resource sciences for 2002.

\begin{tabular}{|c|c|c|c|c|c|}
\hline \multirow[b]{2}{*}{ Journal } & \multirow[b]{2}{*}{ Type of Publication } & \multirow[b]{2}{*}{ Publisher } & \multicolumn{2}{|c|}{ Subscription Price } & \multirow[b]{2}{*}{ Page charges } \\
\hline & & & lndividual & Library & \\
\hline & & & & $--\$$ & \\
\hline Journal of Arid Environments & Commercial & Elsevier Science Publishers & 435 & 1217 & 0 \\
\hline Oecologia & Commercial & Springer-Verlag & 3815 & 3815 & 0 \\
\hline Plant Ecology (formerly Vegetatio) & Commercial & Kluwer Academic Press & 320 & 2618 & 0 \\
\hline Applied Vegetation Science & Joint & $\begin{array}{l}\text { Opulus Press/International Association of } \\
\text { Vegetation Science }\end{array}$ & 53 & 190 & 0 \\
\hline International Journal of Wildland Fire & Joint & $\begin{array}{l}\text { CSIRO Publishing/International Association of } \\
\text { Wildland Fire }\end{array}$ & 152 & 315 & 50 \\
\hline Landscape Ecology & Joint & $\begin{array}{l}\text { Kluwer Academic Press/International } \\
\text { Association of Landscape Ecology }\end{array}$ & 110 & 592 & 0 \\
\hline Oikos & Joint & Blackwell Scientific/Nordic Society OIKOS & 96 & 588 & 0 \\
\hline Restoration Ecology & Joint & $\begin{array}{l}\text { Blackwell Scientific/Society for Ecological } \\
\text { Restoration }\end{array}$ & 90 & 265 & 35 \\
\hline Weed Science & Joint & Allen Press/Weed Science Society of America & 125 & 150 & 50 \\
\hline Agronomy Journal & Society & American Society of Agronomy & 123 & 216 & 0 \\
\hline Ecology & Society & Ecological Society of America & 140 & 565 & 60 \\
\hline Journal of Animal Science & Society & American Society of Animal Science & 110 & 400 & 85 \\
\hline Journal of Range Management & Society & Society for Range Management & 70 & 126 & 80 \\
\hline Journal of Wildlife Management & Society & The Wildlife Society & 87 & 135 & 65 \\
\hline \multirow[t]{3}{*}{ Averages } & Commercial & & 1523 & 2550 & 0 \\
\hline & Joint & & 104 & 350 & 23 \\
\hline & Society & & 106 & 288 & 58 \\
\hline
\end{tabular}


it, commercial companies, six are jointly published by professional non-profit societies and commercial companies, and five are self-published by professional societies. For the journals that are jointly published, the societies provide sponsorship, overall direction, and assistance with technical editing while the commercial companies handle the mechanics of the review process, actual publishing, and business management.

Subscription and page costs for the three types of publishing differ distinctly. The library subscription rates are almost seven times higher for the commercial journals compared to journals affiliated with professional societies. One reason for these higher subscription rates is that the commercial journals do not assess page charges to authors. Subscribers pay the entire cost of publication. Page charges are highest for the journals published by societies and intermediate for the journals that are published jointly.

We assume that societies rely more on page charges to keep the cost of personal subscriptions lower for their individual members. The $J R M$ has the second lowest personal subscription (including society dues) but the second highest page charge. In other words, the $J R M$ places the greatest relative cost burden on the authors. This policy is even more clearly emphasized when we consider that $J R M$ has the lowest library subscription rate of all the journals. JRM should consider increasing the institutional subscription rate and reducing page charges. Journals with lower page charges may be more attractive to researchers with declining budgets. One advantage of joint publishing is the ability to reduce page charges by about one-half without increasing the cost of individual subscriptions.

As the amount of scientific information continues to increase exponentially, rapid access to and organization of information becomes vital to scientists and managers. The development of the Internet has greatly increased access to information. Users are placing major reliance on the internet as their primary source of information gathering. A scientific journal must be available electronically if it is to maintain relevance and impact.

The availability of electronic submission and review of manuscripts is variable among journals (Table 8). Over half formally accept electronic submission of manuscripts. This does not seem to be a major advance unless manuscripts are also reviewed electronically. If paper copies are used for peer review, electronic submission merely saves postage and a few days in the mail. Electronic submission also shifts the cost of paper copies to the journal or peer reviewers and away from the author.

Electronic review is offered by $36 \%$ of the journals. Electronic review is generally an option and is not mandatory. In at least two cases, the Agronomy Journal and the Journal of Animal Science, the electronic review service is offered through a third party supplier. Electronic review should speed the review process by eliminating mail delays and easing the conversion of manuscripts into final articles. It also reduces the need for paper copies. The use of electronic review will likely be a learning process for both authors and peer reviewers but will probably increase over time.

Most journals now have full on-line publication. This means that subscribers or society members can go to the journal web site, log in with a password,

Table 8. Electronic capabilities for various journals in the natural resource sciences.

\begin{tabular}{|c|c|c|c|c|c|c|}
\hline Journal & Type of publication & Submit & Review & On-line viewing & E-mail alerts & Single article (\$) \\
\hline Journal of Arid Environments & Commercial & Yes & Yes & Yes & Yes & $\mathrm{N} / \mathrm{A}$ \\
\hline Oecologia & Commercial & Yes & Yes & Yes & Yes & 30.00 \\
\hline Plant Ecology (formerly Vegetatio) & Commercial & Yes & No & Yes & Yes & 21.50 \\
\hline Applied Vegetation Science & Joint & Yes & No & abstracts & Yes & 6.50 \\
\hline International Journal of Wildland Fire & Joint & Yes & No & Yes & Yes & 15.00 \\
\hline Landscape Ecology & Joint & Yes & Yes & Yes & Yes & 21.50 \\
\hline Oikos & Joint & Yes & No & Yes & Yes & 19.00 \\
\hline Restoration Ecology & Joint & No & No & Yes & Yes & 19.00 \\
\hline Weed Science & Joint & No & No & abstracts & Yes & N/A \\
\hline Agronomy Journal & Society & Yes & Yes & Yes & Yes & 5.00 \\
\hline Ecology & Society & No & No & Yes & No & $\mathrm{N} / \mathrm{A}$ \\
\hline Journal of Animal Science & Society & Yes & Yes & Yes & No & N/A \\
\hline Journal of Range Management & Society & No & No & abstracts & No & $\mathbf{N} / \mathbf{A}$ \\
\hline Journal of Wildlife Management & Society & No & No & No & No & N/A \\
\hline
\end{tabular}


and access the full text of the journal electronically. The articles can be read on-line or printed. This service is available as part of the regular subscription or sometimes at a moderate additional cost. In at least one case, the American Society of Animal Science, subscription costs are $\$ 50$ lower for the electronic version of the Journal of Animal Science compared to the paper version. Full text access can also be obtained through membership in a journal indexing service.

Finally, several journals make the full text of individual articles available on a fee-per-article basis. Users can obtain access to an article of interest by simply entering a credit card number. The availability of this service and the cost of individual articles are listed in Table 8 under "Single article." The value of full text access is that users have unprecedented power to search for authors, titles, keywords, phrases of text, or even citations. Once an article of interest is located, it can be accessed immediately.

$J R M$ currently has abstracts available on-line but not full text. Users have the ability to search for authors, titles, or text phrases but the search is limited to the abstract of the article and only the abstract can be viewed. Users must go elsewhere to obtain the complete article.

Another valuable tool available with two-thirds of the journals is the use of electronic alerts. Users can request email alerts when the most recent table-ofcontents is available for a given journal.

$J R M$ is clearly behind the majority of other journals in the area of electronic access. Scientists and managers now actively use the internet to gather information quickly and in a timely manner. The fact that $J R M$ has only abstracts readily available means that the science published in the $J R M$ is less likely to be used and the stature of the $J R M$ is reduced. As an example, the USDA-National Agricultural Library has recently developed a digital desktop library called DigiTop. USDA employees, many of whom are involved in rangeland management, can access the full text of hundreds of journals from their own office. Unfortunately, the Journal of Range Management is not available on DigiTop.

Answer: Page charges assessed for publishing in $J R M$ are not cost-competitive with similar journals. Some societies (e.g., American Society of Agronomy, The Wildlife Society) with larger membership than SRM continue to self publish, but most others are joint publishing (e.g., Weed Science). The journals with the most costly subscription rates are commercially published and do not represent a scientific society. Of journals published by scientific societies, either jointly or self-published, JRM has the second lowest personal subscription (including society dues) but the second highest page charges. Joint publishing would likely reduce $J R M$ page charges by about one-half without increasing cost of individual member subscriptions.

Electronic capabilities of journals vary, but $J R M$ lags in this arena, especially in on-line viewing, which is likely resulting in a loss of scientific stature for $J R M$. Expanding to full electronic capability for $J R M$ could increase scientific stature, reduce costs to SRM, and provide a meaningful member service to SRM scientist members.

\section{Is $J R M$ getting a fair share of the income it generates relative to the other SRM publica- tions?}

$J R M$ produced a net profit of $\$ 66,225$ in 2001 . Rangelands and Trail Boss News (TBN) in 2001 represented a net loss of $\$ 69,204$. Ninety percent of the cost of Rangelands and TBN in the 2001 and 2002 budgets was expensed under membership service. Unlike $J R M$, TBN and Rangelands lack their own budget, so it is not possible to accurately calculate the net return for either Rangelands or $T B N$ as separate publications. However, it is safe to say that Rangelands and TBN taken together cost SRM roughly the same expense as $J R M$ generates in net income. Rangelands and TBN will have their own budgets in 2003, so a more accurate estimate of net income will be generated for these two publications separately. 
Answer: $J R M$ generates substantial income that is used to subsidize SRM member services, but as the flagship scientific publication of SRM, JRM appears inadequately financed to properly represent the professionalism that SRM scientist members desire. Potential conflict of interest exists in the current system.

\section{What changes have occurred in $J R M$ 's pub- lishing history?}

One attractive feature of publishing in $J R M$ is the relatively brief backlog of manuscripts, and therefore relative rapid processing of manuscripts from acceptance to printing. Publication following final acceptance of the manuscript requires three to four issues to be prepared in advance of publication. The status of $J R M$ manuscripts in mid-January, 2003, serves as an example of scheduling $J R M$ manuscripts for publication. $J R M$ was in the initial production stages of the March 2003 issue (Gary Frasier, personal communication). Abstracts for the July issue were in the process of being translated into Spanish, and abstracts for the September issue were to be sent for Spanish translation in the next few weeks. In midJanuary, the editor was scheduling into the Nov 2003 issue, which was about $25 \%$ full.

The number of pages printed per issue and per year changed in 1997 when $J R M$ converted from saddle binding, usually with 96 pages per issue (576 per year), to adhesive binding. Since 1997, between 96 and 104 pages per issue were printed for about 600 to 700 pages per year. The editor attempts to print 13 to 15 articles per issue, which results in a convenient number of interpretive summaries to appear in Rangelands.

Although more pages are being printed, the back$\log$ in manuscripts has remained constant for several reasons. First, manuscripts are longer. Number of pages per published article has increased from about three in the 1960's to seven pages in 2002 . Spanish abstracts, included recently in articles, add to the production time. Another reason is an increase in acceptance rate of manuscripts (Fig. 3a). The relatively low rejection rate is yet another attractive feature for authors to submit to $J R M$.

Declining numbers of manuscripts submitted (Fig. 3b) may reflect a decline in overall scientific stature of $J R M$. Changes in research funding from applied and agricultural research to basic and ecological re-
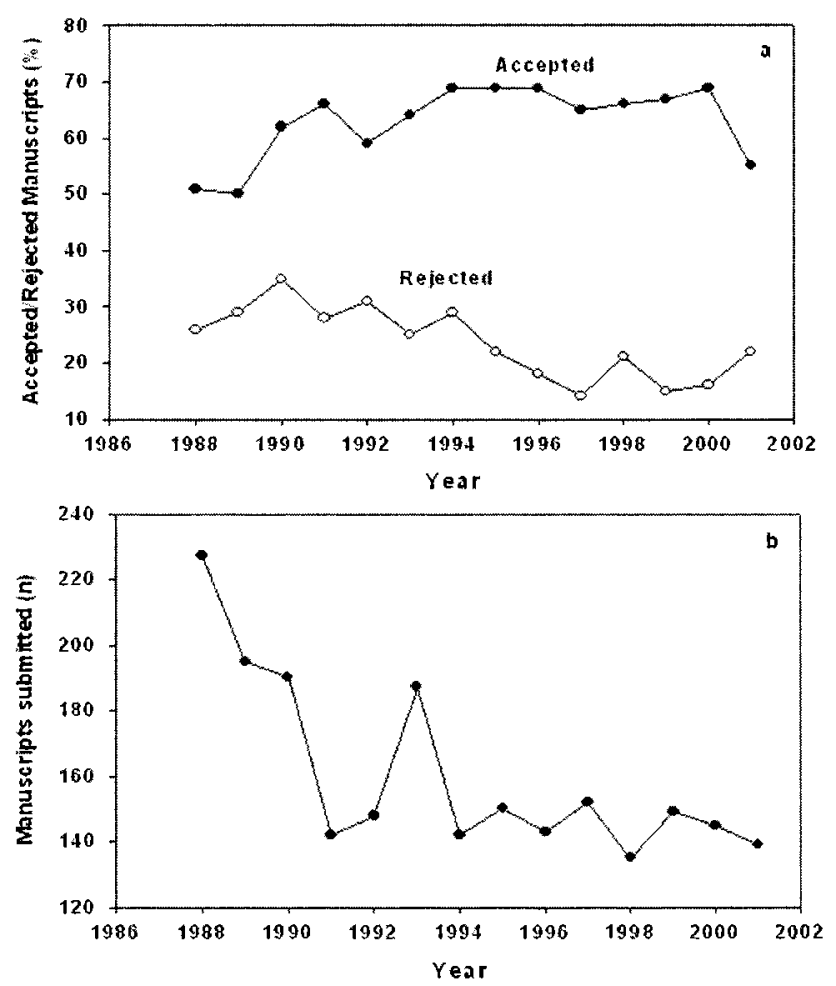

Fig. 3. (a) Number of manuscripts submitted annually for review to JRM since 1988 and (b) percent of manuscripts accepted and rejected in JRM review since 1988. Percentages for 2001 represent incomplete data because some manuscripts remain in review or the results of review are not yet returned to the editor.

search, reduction in the number of ecological articles, and the rapid increase in competing journals have likely contributed to the drop in submissions. The declining rejection rate (Fig. 3a) may indicate that $J R M$ is lowering publication standards and therefore losing scientific stature.

Answer: The number of pages published by $J R M$ increased in 1997 with a change in cover binding. The number of manuscripts submitted declined by about a third in the early 1990's, but acceptance rate and number of pages printed per article stabilized the increased number of pages permitted in 1997. The short publication backlog and low rejection rate compared to other journals are attractive features of publishing in $J R M$, but low rejection rate may increase the perception of declining scientific stature of $J R M$.

\section{Conclusions}

The rapid, extensive change in the research funding and publishing landscape has changed the scientific environment in which SRM's scientific pub- 
lishing competes. Declining budgets for agricultural research and other applied research relative to phenomenal increases in funding for basic ecological research, through the National Science Foundation, for example, has become an important driver of researcher choice of publication outlet.

At the same time, increasing numbers of journals provide authors many more outlets in which to publish range research. Combined with other systemic changes, such as an increase in ecologically oriented $\mathrm{PhD}$ graduates relative to agriculturally oriented $\mathrm{PhD}$ graduates from university range programs, the pressure on SRM to change has escalated to the point it can no longer be ignored. The alternative to change seems likely to involve inevitable obsolescence as the leading source for range research.

$J R M$ has lagged on several fronts in moving into the modern era of scientific publishing. Developments in electronic publishing and indexing have not been used to increase $J R M$ 's visibility in the scientific marketplace. Also, scientific impact and subject matter content indicate $J R M$ is operating in the arena of agricultural science journals. The difference in growth trend of scientific impact among cohort journals indicates that, if SRM is to grow its scientific impact, it must broaden its image in scientific publishing, and the most promising area in which broadening is needed is in the ecology of rangelands.

A related concern is that $J R M$ has deviated from primarily representing the science of the range management profession and therefore is becoming a publication outlet for agricultural scientists and other non-range scientists. Authorship affiliation suggests that $J R M$ is increasingly providing a publishing service to those on the periphery of rangeland management science.

The substantial income generated by $J R M$ has been used to subsidize other SRM member services while investment in scientific publishing has suffered. Although the short backlog of papers and low rejection rate compared to other journals are attractive features of publishing in $J R M$, the current prestige, availability, and impact of $J R M$ is inadequate to justify higher page charges in $J R M$ in relation to similar journals. The lack of electronic access is likely decreasing the impact of $J R M$ and limits its attractiveness as an outlet for scientific publication.
Income from an increased institutional subscriber base is possible with electronic access and could be used to enhance the flagship scientific publication of SRM and produce the value SRM scientist members desire.

\section{Recommendations}

The Task Force recommended to the SRM Board of Directors that structural change (e.g., publishing process) be coupled with substantive change in $J R M$ (vision, journal content, etc.). With respect to vision and content, the Task Force recommended formation of an editorial oversight board, independent of the associate editors and composed of SRM member scientists representing diversity of sub-discipline and seniority, to focus the subject matter of $J R M$ content. Further, a scientific technical editor, chosen initially to implement change in vision and journal content, would focus ultimately on technical content and quality of $J R M$.

With the goals of improving practical aspects of the publication process, the Task Force recommended increasing scientific impact through marketing, and increasing service to scientist members, and joint publishing of $J R M$. The Task Force also recommended, as a priority, providing electronic access to $J R M$ and to electronic indexing, both of which would be available to institutional subscribers.

With regard to increasing scientific impact, the Task Force recommended retaining a journal to publish articles with the traditional management/technical information that deals with the science of range management. The goal of this journal would be to communicate science primarily to range scientists and other scientists publishing research about rangelands (e.g., wildlife ecologists, animal scientists). However, the Task Force also recommended exploring a new journal to engage current SRM-member authors who publish in and read primarily other journals, to attract former SRM-member scientists, and to attract new authors from the ecological sciences. The goal would be to communicate SRM's scientific contributions to a broader scientific audience. 
SRM's primary scientific publishing enterprise has prospered for many years under the leadership of the current editor and JRM staff. Together with dozens of associate editors who have selflessly labored to improve $J R M$ over the years, the editor's devotion to SRM provides a firm foundation for bringing greater visibility and influence to $J R M$. $J R M$ has a long, enviable history of significant contribution to range science. This report indicates even greater success is achievable if provided leadership and the resources required.

\section{References}

Hochstrasser, T., D. Peters, J. Fehmi, and K. VonFinger. 2002. A bibliography of important plant species in the Chihuahuan Desert of North America (1904-2002). U.S. Army Corps of Engineers, Construction Engineering Research Laboratory. ERDC/CERL SR-02-8.

ISI Web of Knowledge. 2002. The Impact Factor. ISI, The Thompson Corporation.

http://www.isinet.com/isi/hot/essays/journalcitationreports/7.html. Accessed July 25, 2002.

ISI Web of Science. 2002. ISI, The Thompson Corporation. http://isiknowledge.com. Accessed October 22, 2002.

Acknowledgements: We thank Anne Prestamo, Head and Associate Professor of Digital Library Services at the Edmond Low Library, Oklahoma State University, for assisting us in acquiring data from the Science Citation Index.

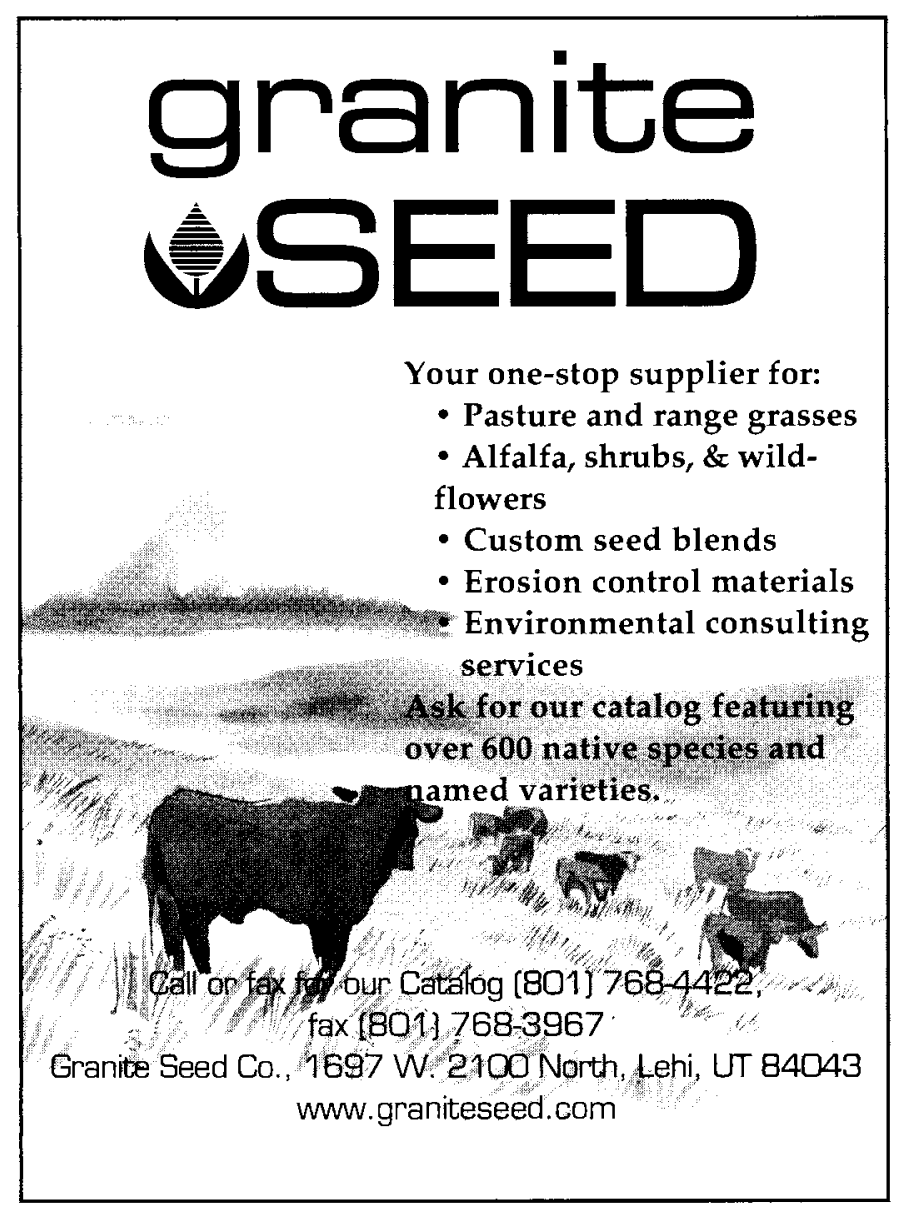

